\title{
Le Violier des histoires rommaines. Edition critique par Geoffroy Hope
}

\section{Gianni Mombello}

\section{(2) OpenEdition}

10 Journals

\section{Édition électronique}

URL : http://journals.openedition.org/studifrancesi/35807

DOI : 10.4000/studifrancesi.35807

ISSN : 2421-5856

Éditeur

Rosenberg \& Sellier

\section{Édition imprimée}

Date de publication : 1 juillet 2005

Pagination : 140-141

ISSN : 0039-2944

\section{Référence électronique}

Gianni Mombello, «Le Violier des histoires rommaines. Edition critique par Geoffroy Hope », Studi

Francesi [En ligne], 145 (XLIX | I) | 2005, mis en ligne le 30 novembre 2015, consulté le 20 avril 2021.

URL : http://journals.openedition.org/studifrancesi/35807 ; DOI : https://doi.org/10.4000/

studifrancesi.35807

Ce document a été généré automatiquement le 20 avril 2021.

\section{(c)}

Studi Francesi è distribuita con Licenza Creative Commons Attribuzione - Non commerciale - Non opere derivate 4.0 Internazionale. 


\title{
Le Violier des histoires rommaines. Edition critique par Geoffroy Hope
}

\author{
Gianni Mombello
}

\section{RÉFÉRENCE}

Le Violier des histoires rommaines. Edition critique par Geoffroy Hope, Genève, Droz, 2002 («Textes Littéraires Français», 548), pp. xxvi-675.

1 Une introduction rapide présente cette version française presque complète (151 textes sur les 181 de la vulgate d'Æsterley; la moralisation du texte numéro 118 et le récit du suivant font défaut) des Gesta Romanorum. L'édition de Gustave Brunet parue dans la «Bibliothèque Elzévirienne» en 1858 a rendu de grands services, mais on ressentait le besoin d'une transcription plus accessible et récente de ce best seller du Moyen Age. Le travail de G. Hope répond exactement à cette nécessité. Le texte que le traducteur «expert et litteré» (selon le privilège royal), choisi par Jean de La Garde avant 1521, offrait aux lecteurs arrivait peut-être un peu en retard. Un bon nombre de ces récits étaient connus par d'autres œuvres, au début $\mathrm{du} \mathrm{XVI}{ }^{\mathrm{e}}$ siècle, et surtout les moralisations (parfois longues) qui les accompagnaient n'étaient plus tout à fait au goût du jour. Toujours est-il qu'à l'editio princeps de 1521 (= A) deux autres ont fait suite: celle de Philippe Le Noir en 1525 (= B) et celle de Denis Janot en 1529 (=C), ce qui atteste, sinon un engoûment, certes un intérêt non négligeable pour ce recueil de contes qui avaient évolué vers la littérarité. L'accord de B et C contre A est fréquent, mais, la plupart du temps, peu significatif, et parfois l'accord des trois témoins ne corrige pas une faute ou une omission évidentes (pp. 32, 63, 68, 96, 190, 346 etc.).

2 La traduction de 1521 n'est pas fidèle, comme on pouvait s'en douter; il s'agit en effet d'une interprétation de l'original selon la tradition médiévale. On peut même se demander quel texte le traducteur a eu sous les yeux, puisque la comparaison avec l'édition đsterley, souvent et très opportunément fournie par l'éditeur, laisse apparaître de nombreuses et étranges divergences. Par exemple: «filios proprios 
pluresque patricios et consules interfecit» est traduit par «Ses propres enfans tua. Plusieurs citoiens et mauvais consules rommains mist a mort cruelle» (p. 121, texte 43); «veritas» par «vertu» (p. 154, texte 56); «jungit» par «enoinctes» (p. 179, texte 61, corrigé dans B et C par «enjoinctes». Est-ce que l'original portait «ungit», ce qui ne convient pas au sens du passage: «quia sicut gumma duo adinvicem jungit...»? Dans la moralisation de ce même texte, «jumentorum» devient «inventorum»; cette variante, ainsi que d'autres, pourraient aider à l'identification du manuscrit ou de la famille de manuscrits que le traducteur a eu sous la main); «amare flevit» par "ploroit moult tendrement» (p. 212, texte 75); «filium formosum peperit» par «elle le (son enfant) produyt enterre» (p. 223, texte 79); «peccata» par «pecheurs» (p. 262, texte 92); «et spiritum emisit» par «car elle devint lepreuse» (p. 311, texte 105); «illud Matth»par «selon l'evangeliste Sainct Marc» (p. 325, texte 110); etc.

G. Hope a corrigé les 'coquilles' de l'editio princeps qu'il reproduit, sans crier garde, ce qui est dommage. Sont-elles nombreuses et de quelle nature? Des philologues auraient bien aimé en savoir davantage.

Geoffroy Hope ajoute au travail de transcription et de collation un commentaire très important (pp. 461-618). Les différents chapitres du Violier portent des titres qui renvoient à la moralisation et non pas au récit, comme dans les Gesta Romanorum. G. Hope a transcrit, au début de l'annotation se rapportant aux différents chapitres, le titre en français placé dans la marge à côté des xylographies qui illustrent quarantehuit chapitres de l'édition de Jean de La Garde. Même si la plupart de ces gravures proviennent de l'édition des Fantasies de Mere Sote de Pierre Gringore, le texte dans la marge se rapporte au récit en question, même si l'illustration est répétée une ou deux fois avant d'autres textes. A la suite de ce «titre» on trouve le renvoi à de différents «Motif-Index» (Tubach, Rotunda, Aarne-Thompson, Goldberg), aux éditions Esterley et Swan-Hooper, à l'Enzyklopädie des Märschens (pour les volumes publiés) et aux Anmerkungen de Bolte et Polívka au recueil de contes des frères Grimm. Ces renvois sont complétés par des informations sur la tradition du récit, des suggestions de lecture et d'interprétation qui concernent tout aussi bien le conte que sa moralisation. C'est la partie la plus originale et la plus précieuse de ce travail.

5 La bibliographie (pp. 619-34) est importante et mise à jour. A la fin du volume on trouve une Table de concordances fondée sur l'Index Exemplorum de Frédéric C. Tubach (pp. 635-40), où chaque entrée est comparée avec les numéros d'ordre du Violier, ceux des Gesta Romanorum et le travail récent (1992) de Brigitte Weiske sur le même ouvrage (Manuscrit d'Innsbruck, lat. 310, daté de 1342, le plus ancien témoin de la tradition continentale), la reproduction de vingt illustrations tirées de l'édition de Jean de La Garde et un Petit glossaire (pp. 663-75). Ce dernier est un peu maigrichon, mais cela n'enlève rien à l'importance de ce travail sur la traduction française des Gesta Romanorum. Geoffroy Hope poursuivait un autre but et avait d'autres intérêts. Comme turinois, j'ai été intrigué, entre autres, par cette mention du chapitre 15 (p. 53, Vie de Saint Alexis), où il est question d'une «ymaige de Nostre Seigneur Jesuchrist faicte sans ouvrage manuel» qui «estoit en ung blanc linge» conservé à Edesse. Cette allusion aura certainement fait plaisir à Louise de Savoie, dédicataire de cette traduction.

6 C'est maintenant aux philologues de se pencher sur ce texte fort intéressant, mais qui reste parfois obscur, même lorsque l'Editeur a ressenti le besoin de solliciter la version latine. Les calques foisonnent, mais certaines locutions (p. 53: «Son pere remplissoit l'an [l'air?] de ses gemissemens» [traduction de «ingemiscens»]; p. 58: «ung mantel 
adriaticque»; p. 59: «Prendz la table de pelerin!»; p. 63: «Je suis deliberé de vous servir s'il vous vient a cueur», locution absente du Dictionnaire des locutions de G. Di Stefano avec le sens probable qu'elle a ici [«si vous le désirez»], etc.) mériteraient quelques mots d'explication.

7 Cette édition a, entre autres mérites, celui d'offrir un document précieux pour l'étude du français au début du XVI ${ }^{\mathrm{e}}$ siècle. 